\title{
CARACTERIZAÇÃO DE UM GRUPO DE IDOSAS HOSPITALIZADAS E SEUS CUIDADORES VISANDO O CUIDADO PÓS ALTA HOSPITALAR
}

\author{
CHARACTERIZATION FOR A GROUP OF HOSPITALIZED OLD WOMEN AND \\ THEIR CARES VISING THE CARE AFTER DISCHARGE
}

\section{CARACTERIZACIÓN DE UN GRUPO DE ANCIANAS HOSPITALIZADAS Y SUS CUIDADORES CON VISTAS AL CUIDADO POST-ALTA HOSPITALARIA}

\author{
Maria José Sanches Marin* \\ Emilia Luigia Saporiti Angerami**
}

Marin MJS, Angerami ELS. Caracterização de um grupo de idosas hospitalizadas e seus cuidadores visando o cuidado pós alta hospitalar. Rev Esc EnfermUSP 2002; 36(1):33-41.

\begin{abstract}
RESUMO
No presente estudo foram estudadas 50 idosas internadas em unidade de clinica médica e seus respectivos cuidadores. Verificou-se que a maioria das idosas apresentavam dependências diversas e, portanto, necessitavam da presença de um cuidador para sua sobrevivência. Os cuidadores, em sua maioria, eram do sexo feminino, pertenciam à família da idosa, tinham algum grau de escolaridade e apontaram diversas dificuldades no cuidado da mesma. Constata-se, portanto, que durante a hospitalização, há necessidade de se adotarem medidas visando ao preparo do cuidador para assumir a complexa assistência requerida pelo idoso, principalmente após a alta hospitalar.
\end{abstract}

PALAVRAS-CHAVE: Cuidadores. Idoso. Assistência a idosos.

\begin{abstract}
In the present study 50 old women interned in a medical treatment unity and their respective caregivers were studied. It was verified that most of the women preseted various dependencies and, threfore, they needed the presence of a caregiver for their survival. The caregivers, most of them female, belonged to the old women's family, had some scholarship degree and pointed out several difficulties en caring for the women. It is verified, consequently, that during hospitalization there is the need to take measures aiming at preparing the caregiver to take on the complex aid required by the old person, especially after hospital discharge.
\end{abstract}

KEYWORDS: Caregivers. Aged. Old age assistance.

\section{RESUMEN}

La presente investigación trata del estudio de 50 mujeres ancianas internadas en clínica médica y sus respectivos cuidadores. Se verifico que la mayoria de las ancianas presentaban dependencias diversas $y$, por tanto, necesitaban de la presencia de un cuidador para sobrevivir. Los cuidadores, en su mayoria, eran del sexo femenino, pertenecian a la familia de la anciana, tenían algún grado de escolaridad e indicaron varias dificultades en el cuidado de la misma. Se constató que durante la hospitalización hay la necesidad de adoptar medidas con vistas al preparo del cuidador para asumir la compleja atención que requiere el anciano, principalmente después del alta hospitalaria.

PALABRAS-CLAVE: Cuidador. Anciano hospitalizado.

Enfermeira Docente Assistêncial do Curso de Enfermagem da Faculdade de Medicina de Marília e Doutoranda em Enfermagem pelo Departamento de Enfermagem Geral e Especializada da Universidade de são Paulo de Ribeirão Preto, Estado de São Paulo, Brasil.

** Professora Titular do Departamento de Enfermagem Geral e Especializada da Escola de Enfermagem da Universidade de São Paulo, Ribeirão Preto, Estado de São Paulo, Brasil.Email - marnadia @ zaz. com.br 


\section{INTRODUÇÃO}

Nossa atuação em Unidade de Clínica Médica permite o contato freqüente com idosos e a vivência da intensidade de seus problemas, uma vez que são propensos a dependências diversas, com conseqüente necessidade de apoio de um cuidador em sua manutenção.

A preocupação com a velhice, apesar de constituir-se em questão antiga, vem aumentando no mundo todo nos últimos decênios devido à constatação do aumento da média de vida da população, atribuída às melhores condições sanitárias, à profilaxia de doenças, ao surgimento de novas drogas e ao planejamento familiar.(1-4)

No Brasil, a modificação da expectativa de vida ao nascer ao longo do século chama a atenção. Em 1900 , os indivíduos com mais de 60 anos perfaziam um percentual de $3 \%$ e a expectativa de vida era de 33,7 anos. Em 1970, verificou-se um percentual de $5,2 \%$ e uma expectativa de vida de 57,1 anos, sendo que, no censo de 1980 , esse percentual subiu para $6,5 \%$ e a expectativa de vida, para 63,5.(1,5) Dados da Fundação Instituto Brasileiro de Geografia e Estatística(6) confirmam que em 1990 a população de idosos representava $7,05 \%$ da população do Brasil e, conforme Veras (5), a expectativa de vida era de 68,6 anos para esse período.

Tem-se constatado que as pessoas envelhecidas, mesmo as que têm boa saúde, debilitam-se paulatinamente devido às alterações fisiológicas que, com o avanço da idade, limitam as funções do organismo, tornando-as cada vez mais predispostas à dependência para a realização do autocuidado, à perda da autonomia e da qualidade de vida. Tornam-se também, mais suscetiveis a doenças e, decorrente disso, vem a hospitalização.

Walters ${ }^{(7)}$ reconhece que a assistência oferecida no ambiente hospitalar cria dependências que dificultam o retorno ao lar. Assim, se por causa de uma enfermidade o idoso precisa ser hospitalizado, o hospital deve prepará-lo o mais eficientemente para que ele possa retornar ao lar em condições fisicas, psíquicas e sociais de independência.

Como o sistema de saúde brasileiro, que se encontra centrado na assistência hospitalar, vem passando atualmente por mudanças, novas propostas de atenção visando à desospitalização têm surgido. Entre elas destaca-se a internação domiciliar que visa, além da humanização da assistência, a otimização dos leitos hospitalares e a redução dos custos da assistência.

Observa-se que, atualmente, quem tem assumido a responsabilidade pelo cuidado do idoso é algum elemento da família ou alguém contratado pela mesma. Esse indivíduo que assiste o idoso tem sido denominado pela literatura como "cuidador", distinguindo-se, conforme citação de Duarte(8) dois tipos: "cuidador formal", aquele elemento contratado pelo idoso e/ou família para exercer ações de cuidado, estabelecendo-se nesse caso um vínculo empregatício e o denominado "cuidador informal", aquele elemento da família do idoso ou a ele relacionado que passa a assumir o desenvolvimento das ações do cuidado.

O cuidador do idoso, muitas vezes parte da familia, além de ser fundamental para sua qualidade de vida, precisa estar preparado por profissionais da saúde para assumir a complexa assistência exigida, principalmente quando esse é dependente para as atividades de vida diária.

A familia moderna, porém, tem-se deparado com dificuldades para essa assistência por encontrar-se menos numerosa e estar a mulher integrando o mercado de trabalho fora do lar. O aumento do número de divórcios e/ou separações também faz diminuir o apoio ao idosos.

Barusch(9) constatou que, em vários países, já existem incentivos governamentais, na forma de pagamento, para os membros da família que proporcionam assistência ao idoso. No Brasil esse aspecto não se encontra contemplado na política nacional do idoso, regulamentada pelo decreto n. 1.948 , de 3 de julho de 1.996 o qual, no entanto, determina que os programas de amparo aos idosos sejam executados, preferencialmente, em seus lares. ${ }^{(10)}$

O cuidador, como se sabe, tem recebido, dos profissionais de saúde que atuam na área hospitalar, pouca atenção no sentido de capacitá-los para a continuidade da assistência, embora assuma papel de grande importância na assistência ao idoso em cujo processo deveria estar envolvido desde o momento da admissão. Ao acompanhar o idoso, há maior possibilidade de comunicação dele com os profissionais da equipe de saúde. Além disso, este contato pode proporcior maior suporte emocional e estímulo psicológico a quem passa a maior parte do tempo inativo.

Laitinen(11) reconheceu diversas ações relacionadas com as atividades de vida diária ( banho, alimentação, auxílio na deambulação, cuidados com cabelos, unhas, dentes e pele) desenvolvidas pelo cuidador ao idoso hospitalizado, com beneficios ao seu bem-estar e qualidade de vida. Segundo ela, os profissionais envolvidos com tal assistência devem estar preparados e atentos para as orientações, treinamento de habilidade e suporte emocional de que podem precisar.

A nosso ver, essa constatação não deixa dúvidas quanto a necessidade de se envolver o cuidador na assistência ao idoso, visto que muito facilitaria a proposta de planejamento de alta. Quem vai assumir 
a responsabilidade pelo idoso deve receber preparo para lhe prestar cuidados de forma adequada. Desta forma, um plano de ação visando ao atendimento do idoso, além de identificar-lhes as necessidades, deve prever também as orientações e desenvolvimento de habilidades do cuidador.

Considerando então a relevância do cuidador enquanto integrante do processo de assistência ao idoso, o presente estudo propõe-se a caracterizar um grupo de idosas hospitalizadas quanto à idade, escolaridade, condições de comunicação e dependência para atividades de vida diária, bem como seus cuidadores quanto à faixa etária, escolaridade, sexo, grau de parentesco e dificuldades na prática de cuidados com a idosa.

\section{METODOLOGIA}

\section{Local}

A presente pesquisa foi realizada na unidade de Clínica Médica e Cirúrgica Feminina (unidade D) do Hospital das Clínicas I da Faculdade de Medicina de Marília.

O Hospital das Clínicas I conta atualmente com 148 leitos de internação, distribuídos entre as sub unidades de pediatria, berçário, unidade de terapia intensiva, moléstias infecciosas, psiquiatria, ginecologia, obstetrícia, clínica médica e cirúrgica, geral e especializada. Do total de leitos, 86 são destinados a pacientes clínicos e cirúrgicos, no atendimento geral e especializado, encontrando-se distribuídos nas subunidades $\mathrm{A}, \mathrm{B}, \mathrm{C}, \mathrm{e} \mathrm{D}$, nas quais a proporção média de idosos atendidos representa $40 \%$ do total de pacientes.

A unidade D (Unidade de Clínica Médica e Cirúrgica Feminina) foi escolhida como campo de estudo por tratar-se do local de atuação da pesquisadora há alguns anos. A referida Unidade conta, atualmente, com 16 leitos destinados ao atendimento de idosas, com alterações clínicas e cirúrgicas de urgência e emergência, provenientes do pronto socorro.

\section{População do estudo}

O estudo contou com a participação de 50 idosas que residiam em Marília e foram internadas na referida unidade, no período de abril a junho de 1998 e, sempre que necessário, acompanhadas de seus respectivos cuidadores, por solicitação da enfermeira da unidade ou pelo desejo dos próprios familiares.

Considerou-se como idosa, quem tivesse 60 anos ou mais de idade, de acordo com critérios estabelecidos pela Lei $n^{\circ} 8.842$ que dispõe sobre a Política Nacional do Idoso ${ }^{(12)}$

\section{Foram excluidas do estudo as idosas que se} internaram em estado grave com forte ameaça à vida.

Os cuidadores participaram do estudo sempre que a idosa apresentava algum grau de dependência fisica e/ou cognitiva. Das 50 idosas que participaram do estudo, $42(82 \%)$ apresentaram algum grau de dependência. Somente $8(16 \%)$ eram totalmente independentes par as atividades de vida diária e, assim, conseguiam assumir toda a responsabilidade pelos cuidados. Os cuidadores foram entrevistados no momento da internação. Em alguns casos, quando isso não era possivel, o serviço social solicitava seu comparecimento ao hospital.

\section{Instrumento de coleta de dados}

Para a coleta de dados utilizou-se um instrumento estruturado (anexo I) contendo dados da idosa (idade, escolaridade, condições de comunicação e dependência para as atividades de vida diária) e do cuidador (idade, escolaridade, sexo, grau de parentesco com a idosa e dificuldades para cuidar da idosa após a alta hospitalar, incluindo a habilidade para cuidar da idosa, as acomodações da casa, a cooperação de outros, o relacionamento familiar a situação financeira, a mudança no estilo de vida, o retorno ao serviço de saúde e outras).

\section{Aspectos éticos}

Para efetivar a coleta de dados foi solicitada autorização à comissão de ética da Faculdade de Medicina de Marília, a qual manifestou-se favorável à mesma.

Antes de iniciar a coleta de dados as idosas e/ ou cuidadores foram orientados quanto à finalidade, ao procedimento e informados de que estariam livres para participar ou não do estudo. Quando houve interesse em participar, solicitou-se a assinatura da pessoa para o termo de consentimento.

\section{Procedimento}

A coleta de dados da idosa e do cuidador foi realizada no momento da internação.

Os dados foram coletados através da entrevista face a face o que segundo Polit; Hangler (13) permite a observação do entrevistado, o que garante maior profundidade e qualidade dos dados colhidos

\section{RESULTADOS E DISCUSSÃO}

\section{Caracterização do grupo de idosas}

Ao observar o gráfico I, constata-se, entre as idosas em estudo, $13(26 \%)$ pertencentes à faixa etária dos 70 a 74 anos, $12(24 \%)$ na faixa etária entre 60 e 
64 anos, dez (20\%) na faixa etária entre 65 e 69 anos, sendo que apenas quatro (8\%) delas tinham 90 anos ou mais. A faixa de idade a que o idoso pertence representa um aspecto importante a se considerar devido ao maior risco de adoecer e de apresentar maior grau de dependência, quanto mais avançada ela se apresenta.

Gráfico I - Distribuição das idosas de acordo com a faixa etária das idosas

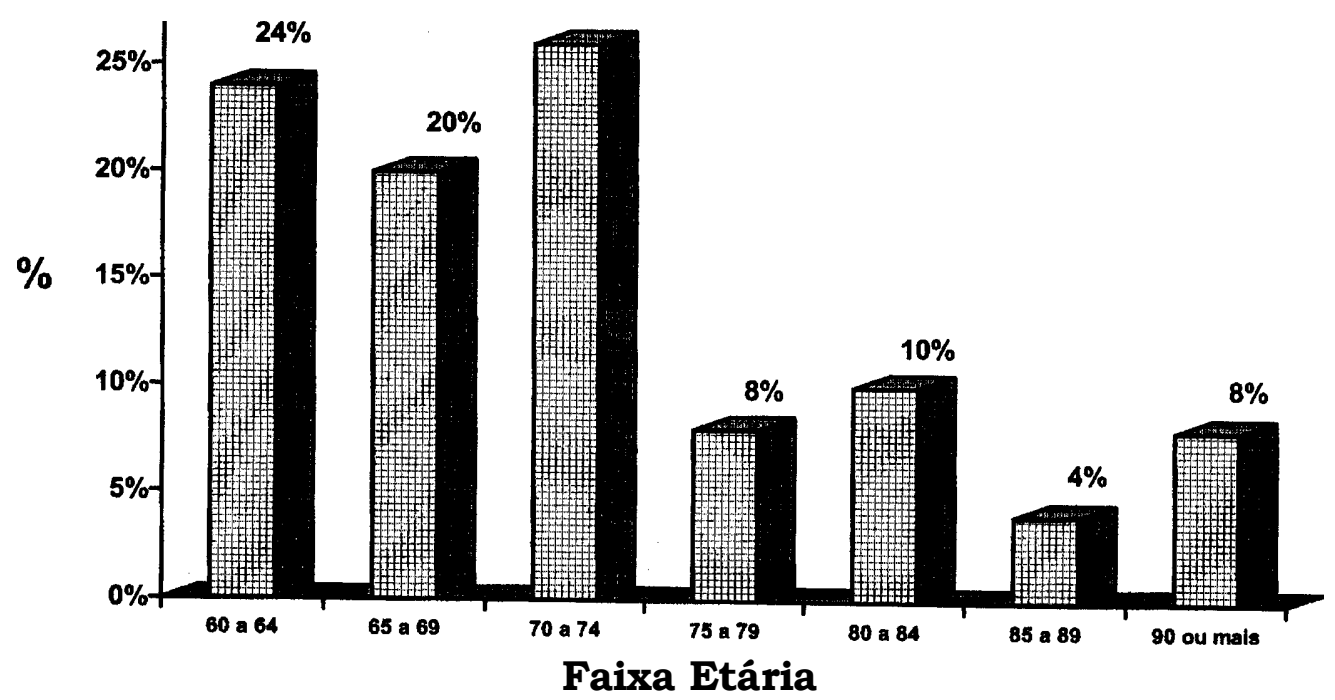

Quanto ao grau de comunicação, 35 (70\%) das idosas apresentaram-se em boas condições de comunicação verbal, expressando dessa forma seu modo de pensar e sentir, enquanto cinco delas $(10 \%)$ eram pouco comunicativas, respondendo apenas o que lhes era questionado e manifestavam, ao mesmo tempo, expressão facial triste, mantendo-se isoladas. Ainda $10(20 \%)$ das idosas não apresentavam condições de comunicação verbal, devido à alterações cognitivas, sensoriais, emocionais e de memória. Note-se que a capacidade de comunicação representa importante indicativo da qualidade de vida, uma vez que permite as pessoas cumprimento de seus papéis sociais.

Em estudo realizado com 1661 idosos acima de 65 anos residentes no municipio de São Paulo, entrevistados domiciliarmente, foi constatado que $32,7 \%$ deles referiram dificuldades na conversação devido a problemas auditivos ${ }^{(14)}$. Esses dados remetem à necessidade de relacionar entre si as alterações encontradas, uma vez que uma poderá funcionar como desencadeadora de outras.

Gráfico II - Distribuição das idosas de acordo com a escolaridade

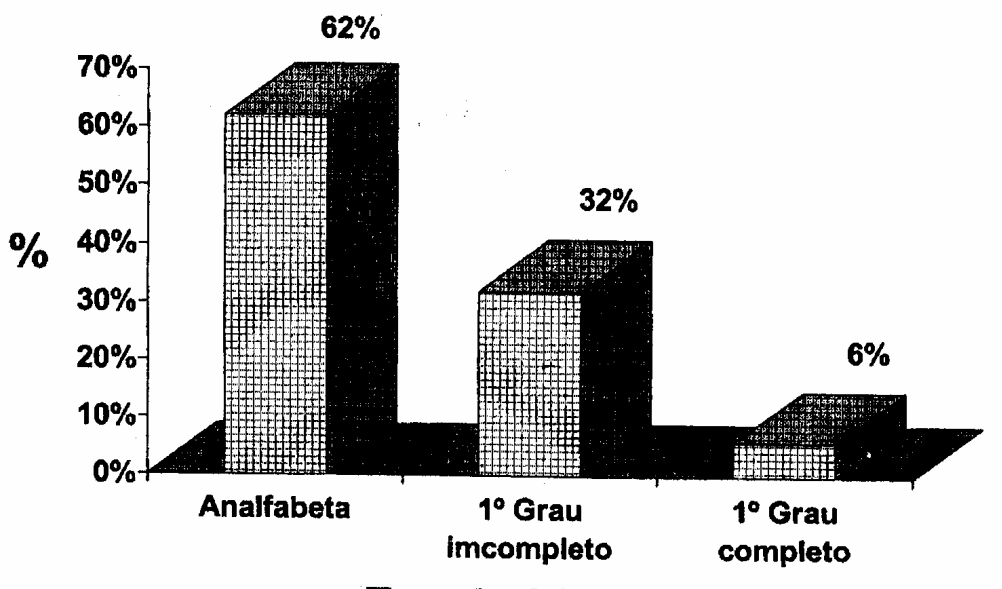

Escolaridade 
Quanto à escolaridade, o gráfico II mostra que $31(62 \%)$ das idosas eram analfabetas, $16(32 \%)$ tinham o primeiro grau incompleto e apenas três $(6 \%)$ tinham o primeiro grau completo. Esses indices mostram o grande número de analfabetos existente na população brasileira, principalmente quando se refere às idosas que viveram sua infância em época na qual o ensino não era prioridade e a mulher se encontrava marginalizada em relação à educação, ao trabalho e à politica, haja vista a citação de Wright; Carneiro(15) "em 1929, as mulheres que ingressavam no curso superior iam para os cursos de farmácia, porque era uma profissão que tinha sofrido grande desvalorização e não interessava para os homens". Somente por volta da metade do século XX, o ensino primário tornou-se obrigatório para a mulher.
O analfabetismo no idoso, segundo Kinsella(18), representa uma realidade dos países em desenvolvimento como por exemplo o Brasil com 50\% em 1980, 64\% em Honduras em 1988 e 38\% no Peru em 1986. Na Guatemala, em 1981, menos de 3\% haviam completado a escola secundária. Há de se considerar ainda que as mulheres estão em desvantagem em relação aos homens.

O grau de escolaridade tem implicações na assistência de enfermagem as quais necessitam ser consideradas ao se realizarem atividades educativas, juntamente com outras alterações próprias do processo de envelhecimento, como a diminuição da acuidade visual e auditiva, por interferirem na aprendizagem.

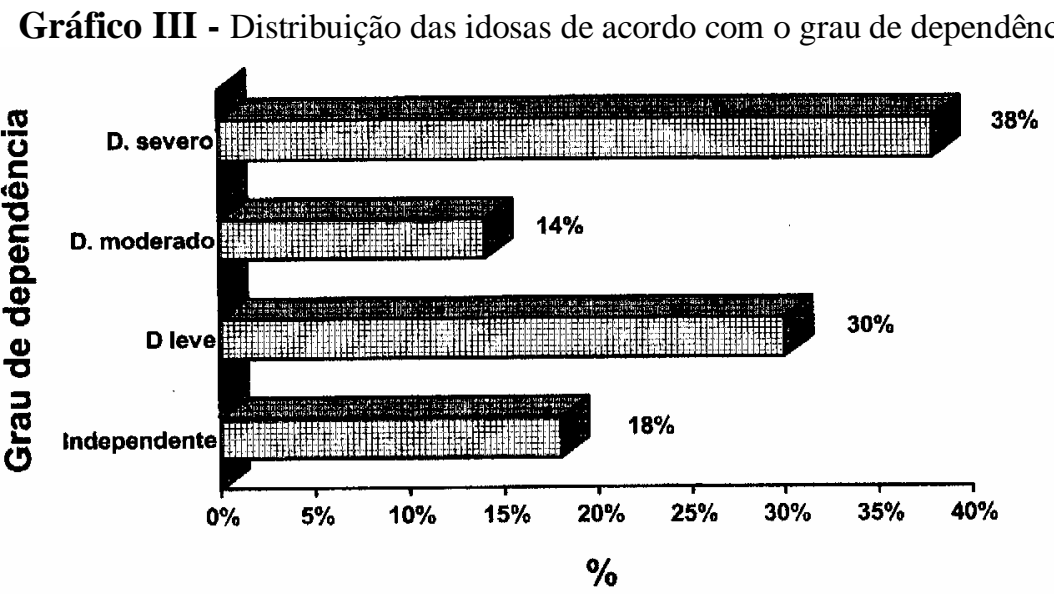

A avaliação da dependência para a realização das atividades de vida diária é considerada, em geriatria, o ponto básico para o estabelecimento de programas de assistência, uma vez que tais atividades revelam as habilidades, a independência, o bem-estar, a auto-estima e, consequentemente, a qualidade de vida dessas pessoas.

A capacidade funcional do idoso, quando afetada, interfere em outros aspectos de sua vida como estabilidade financeira e integração social. Para mensurar o grau de dependência funcional do idoso, muitas escalas têm sido desenvolvidas e adaptadas. Ramos $^{(16)}$ utilizaram a técnica de desenvolvimento de escalas proposta por Guttman ${ }^{(17)}$ e validaram uma escala com 12 indicadores de dependência para o idoso a qual considera as atividades instrumentais de vida diária (fazer compras, pegar ônibus, administrar as finanças e tomar os medicamentos adequadamente) e as atividades de vida diária básica (continência, vestir-se, tomar banho, comer, pentear-se, ir ao banheiro, passar para a cama e sair dela), organizadas hierarquicamente.

De acordo com as doze atividades de vida diária citadas acima, Ramos ${ }^{(16)}$ classifica os idosos em quatro categorias: 1- independente totalmente - idoso capaz de realizar todas as atividades; 2 - dependente leve - idoso que necessita de ajuda para realizar de uma a três atividades de vida diária; 3 - dependente moderado - idoso que necessita de ajuda para realizar de quatro a seis atividades de vida diária e 4 - dependente severo, aquele que necessita de ajuda para realizar sete ou mais dessas atividades.

Considerando tal classificação, encontraram-se, no estudo, 19 (38\%) idosas com dependência severa, sete $(14 \%)$ com dependência moderada, 15 (30\%) com dependência leve e nove $(18 \%)$ independentes para as atividades de vida diária básica e instrumental. Esses dados revelam o alto grau de dependência das idosas e, consequentemente, a necessidade de atuação interdisciplinar com a finalidade de proporciona-lhes reabilitação, tornando tais pacientes mais ativos e produtivos. Além disso destaca-se a importância de um cuidador capaz de auxiliar e estimular a independência dessas pessoas.

Montesant(19) estudaram 76 pacientes acima de 60 anos internados em enfermaria de clínica médica e identificaram 24 (35,8\%) independentes, 17 (25.4\%) 
dependentes leves, seis $(9 \%)$ dependentes moderados

e $20(29,9 \%)$ com dependência grave. Tais dados confirmam a existência de grande número de idosos dependentes, do que se depreende a necessidade de um cuidador para o atendimento de suas necessidades.

\section{Caracterização dos cuidadores}

No que diz respeito ao cuidadores dos idosos, num total de $42(100 \%), 10(23,8 \%)$ eram do sexo masculino, sendo oito (19\%) o próprio companheiro.
Já $32(76,2 \%)$ eram do sexo feminino, quase sempre a filha - 25 (59,4\%); encontraram-se, porém, idosas que eram cuidadas pela irmã, sobrinha ou nora.

No gráfico IV, relativo à faixa etária dos cuidadores, observa-se que dezesseis (32\%) situam-se na faixa etária dos 31 ao 40 anos de idade, dez $(20 \%)$ na faixa dos 41 aos 50 anos e nove (18\%) são indivíduos com idade entre 61 e 70 anos, o que demonstra muitos idosos sendo cuidados por outros.

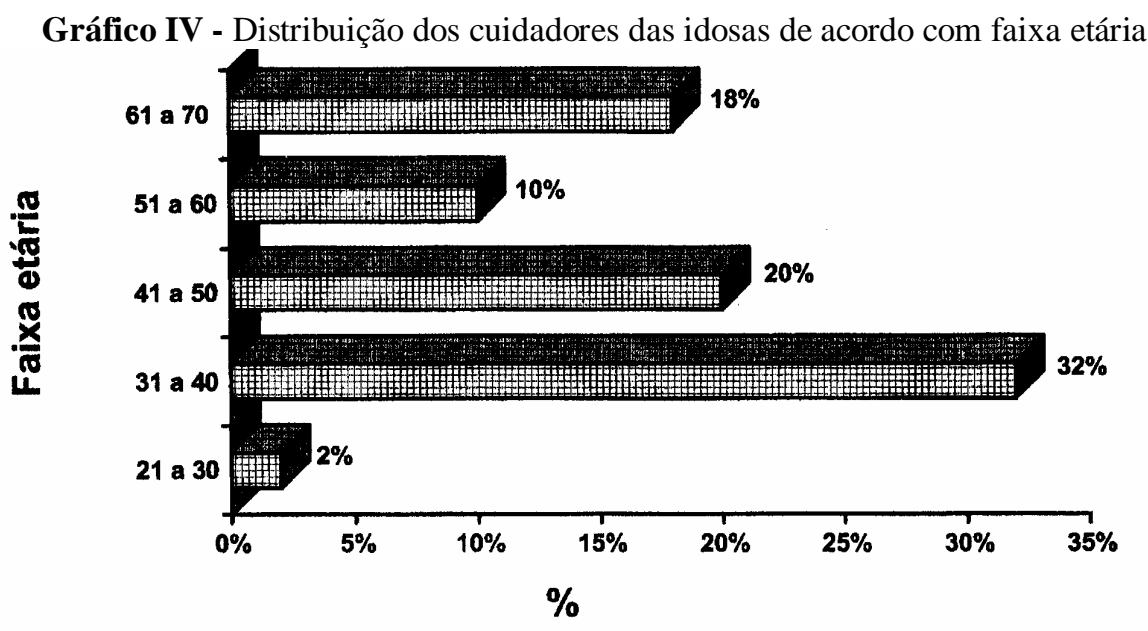

Quanto à escolaridade, 13 (31\%) tinham o primeiro grau completo; dez $(23,8 \%)$, o primeiro grau incompleto; três dos cuidadores $(7,1 \%)$ eram analfabetos, e os demais tinham o segundo grau completo ou o terceiro grau.

Given(20) ao revisar a literatura sobre as características de cuidadores de idosos identificaram que normalmente trata-se de mulheres, com idade em torno de 55 anos e que recebem suporte de outros membros da família, amigos e vizinhos. Além disso, a maior longevidade da mulher, faz com que os homens sejam cuidados pos suas esposas, enquanto que as mulheres têm sido cuidadas por filhas, netas e sobrinhas.

Gráfico V - Distribuição dos cuidadores de acordo com as dificuldades referidas para cuidar das idosas

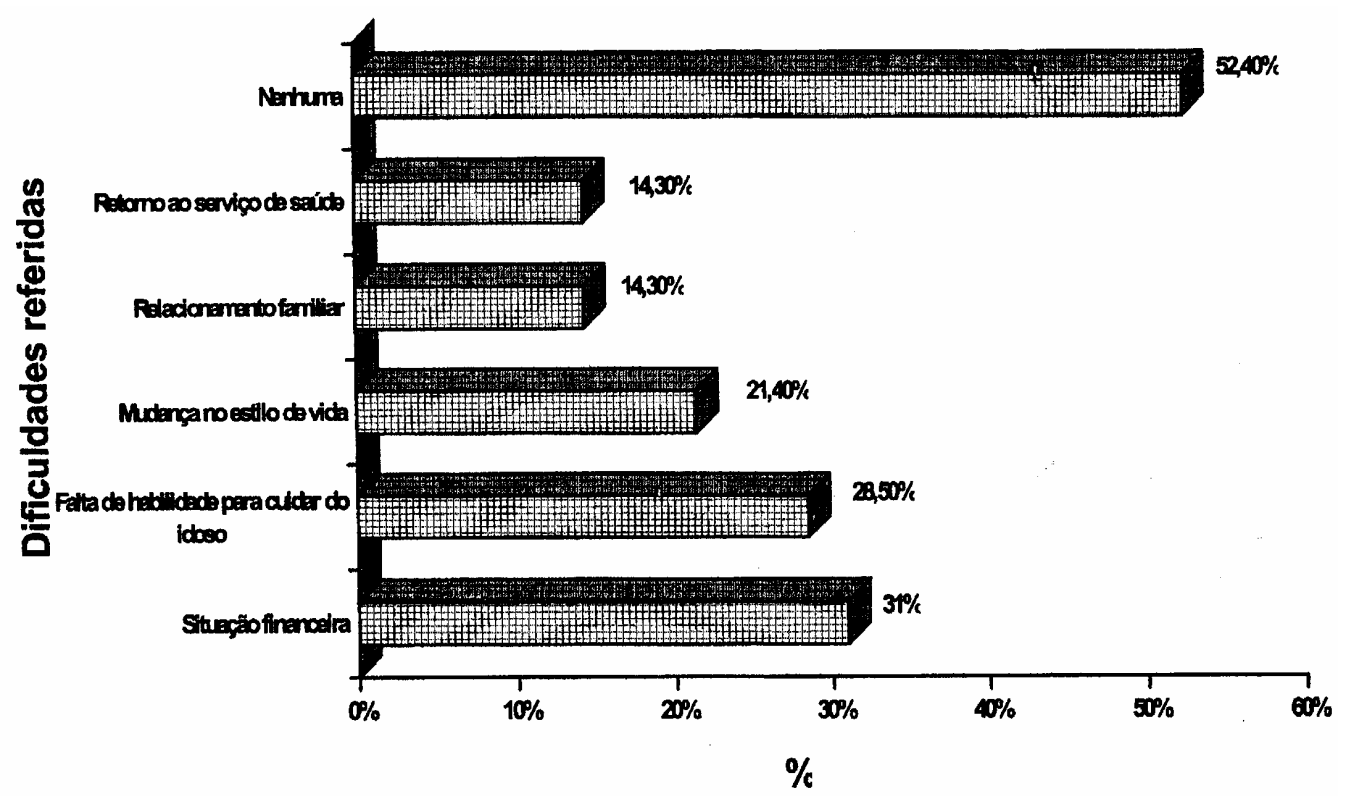


Quanto às dificuldades referidas pelos cuidadores para cuidar das idosas pertencentes ao estudo, observa-se no gráfico $V$ que 13 (31\%) apontaram a situação financeira, $12 \quad(28,5 \%)$ verbalizaram falta de habilidade para cuidar da idosa, conforme segue: "também sou muito doente e não tenho forças para cuidar de minha mãe da forma como se deve", "eu sinto muita fraqueza", "tenho pressão alta, doença de chagas e sinto muita tontura". Mudança no estilo de vida foi referida por nove dos cuidadores $(21,4 \%)$, os quais declararam que teriam de alterar sua forma de trabalho e/ou lazer e adaptar o espaço físico da residência para acomodar o idoso.

Dos cuidadores entrevistados, seis $(14,3 \%)$ afirmaram que o relacionamento familiar seria uma dificuldade pois nem todos os filhos estariam dispostos a contribuir com a assistência ao idoso. A dificuldade de retornar ao serviço de saúde foi mencionada por seis $(14,6 \%)$. Entre os cuidadores, $22(52,4 \%)$ julgaram que não iriam encontrar dificuldades após a alta hospitalar.

Foi possivel constatar que os familiares, de uma forma ou outra, organizam-se, na maioria das vezes, para prestar a ele os cuidados necessários ao idoso e procuram passar-lhe uma visão otimista e não como um "peso" à família. Ao internar o idoso, a família, exceto em alguns casos, pareceu-nos querer se organizar e ganhar forças para continuar a batalha de cuidados com os mesmos, principalmente com aqueles idosos mais dependentes, cujo cuidado sabemos ser uma tarefa intensa.

Mesmo assim, observa-se que o encargo de cuidar do idoso quase sempre recai nas mãos de uma só pessoa, enquanto que os demais membros da família afastam-se e omitem-se da responsabilidade.

Os filhos alegam falta de tempo devido a outros compromissos assumidos ou falta de condições financeiras, já os netos costumam afastar-se do idoso devido às implicâncias e às desavenças próprias dos conflitos das distintas gerações.

\section{CONSIDERAÇÕES FINAIS}

No presente estudo, foram incluídas 50 idosas, sendo $13(26 \%)$ pertencentes à faixa etária de 70 a 74 anos, $12(24 \%)$ dos 60 a 64 anos , dez $(20 \%)$ dos 65 a 69 ano e as demais encontravam-se com 75 anos ou mais. Entre elas, $35(70 \%)$ tinham boas condições de comunicação $31(62 \%)$ eram analfabetas.

Ao verificar o grau de dependência, houve predomínio daquelas com dependência severa 19 (38\%) sendo que apenas oito $(16 \%)$ eram totalmente independentes para as atividades instrumentais e fisicas da vida diária.
As idosas, devido ao grau de dependência apresentado, contavam com o auxilio de um cuidador, normalmente uma pessoa da família. A maioria dos cuidadores, $32(76,2 \%)$ eram do sexo feminino, tinham algum grau de escolaridade e eram suas filhas. Os cuidadores apontaram, como dificuldades para cuidar da idosa, a situação financeira, a falta de habilidade, a mudança no estilo de vida e o relacionamento familiar.

Sabemos da enorme carga que o cuidado ao idoso representa tanto do ponto de vista físico quanto emocional, decorrente do grau de dependência que exige atenção, carinho e cuidado físico.

Notamos que os cuidadores, cada um de acordo com suas possibilidades, participaram, demonstraram interesse e contribuíram com o processo de assistência proposto. O cuidador representa, então, um recurso importante a ser utilizado no processo de assistência intra-hospitalar com a finalidade de prepará-lo para a continuidade da assistência.

Quando a família não dispõe de recursos mínimos necessários para a sobrevivência digna do idoso, torna-se quase impossivel, em nossa realidade, oferecer outra alternativa de assistência, senão a domiciliar.

Acreditamos, assim, ser necessário um trabalho de conscientização dos familiares para haver união de esforços e divisão das responsabilidades, tornando mais amena essa assistência. Um trabalho com essa dimensão necessita de atuação interdisciplinar, que enfoque os múltiplos aspectos como a saúde, bem-estar e qualidade de vida do idoso, no seu contexto social, considerando principalmente sua família.

Outras medidas, como prescrever medicamentos existentes na rede básica, encaminhar para utilizar recursos fornecidos pela Secretaria do Bem Estar Social e contato com recursos da comunidade ( Pastoral da Saúde e Vicentinos), podem auxiliar de alguma forma a assistência ao idoso após a hospitalização. Além disso, é necessária a conscientização das autoridades de saúde para adoção de novas modalidades de assistência, bem como da sociedade, de maneira geral, para as questões do idoso. 


\section{REFERÊNCIAS BIBLIOGRÁFICAS}

(1) Gomes FAA, Ferreira PCA. Manual de geriatria e gerontologia. Rio de Janeiro: EBM; 1985.

(2) Burnside IM, editor. Enfermagem e os idosos. São Paulo: Andrei; 1979.

(3)Berquó ES, Leite VM. Algumas considerações sobre a demografia da população idosa no Brasil. Cienc Cult 1988; 40(7): 679-688.

(4) Ramos LR, Veras RP, Kalache A. Envelhecimento populacional: uma realidade brasileira. Rev Saúde Pública 1987; 21(3): 211-224-

(5) Veras RP País jovem com cabelos brancos: a saúde do idoso no Brasil. Rio de Janeiro: Relume Dumará; 1994.

(6) Fundação Instituto Brasileiro de Geografia e Estatística. Anuário estatístico do Brasil. Rio de Janeiro: 1991.

(7) Walters KR. Discharge planning: an exploratory study of the process of discharge planning on geriatric wards. J Adv Nurs 1987; 12(1): 71-83.

(8) Duarte YAO. Cuidadores de idosos: uma questão a ser analisada. Mundo Saúde 1997; 21(4): 226-230.

(9) Barusch AS. Programming for family care of elderly dependents: mandates, incentives, and service rationing. Soc Work 1995; 40(3):315-322.

(10) Cardoso FH. Decreto n.1.948, de 3 de julho de 1996. Gerontologia 1997; 5(1): 41-44.

(11) Laitinen P. Participation of informal caregivers in the hospital care of elderly patients and their evaluations of the care given: pilot study in three different hospitals. J Adv Nurs 1992; 17(10): 1233-1237.

(12) Brasil. Lei $n^{9}$ 8.842, de 4 de janeiro de 1994. Dispõe sobre a Politica Nacional do Idoso, cria o Conselho Nacional do Idoso e dá outras providências. [On line]. Disponivel em http:// www.dhnet-org.br/direitos/lexdh/lexdh10.htm. (29 set 2000)

(13)
Polit DF, Hungler BP. Nursing research: principles and methods. 3.ed. Philadelphia: Lippincott, 1987. Same additional types of research; Cap.10, p.155-158.

(14) Ebel SJ, Signorini TB, Almeida CAL, Matuk MR, Giorgi MA, Ramos LR. Prevalência da queixa de dificuldade auditiva e fatores associados em uma população idosa acima de 65 anos, residentes no município de São Paulo: EDIPOSO /resumo/ Gerontologia 1994; 2(3): 151.

(15) Wright MGM, Carneiro A. O espaço da mulher brasileira e o espaço da enfermeira brasileira. Rev Bras Enfermagem 1985; 38(1): 55-62.

(16) Ramos LR, Perracini M, Rosa TE, Kalache A. Significance and management of disability amoung urban elderly residents in Brazil. J Cross Cult Gerontol 1993; 8: 313-323.

(17) Guttman A. The basis of scalogram analysis. In: Stouffer SA, Star SA, Guttman L. Measurement and predictionPrinceton: Princeton University Press; 1950. p.60-90.

(18) Kinsella K. Dimensiones demográficas y de salad en América Latina $y$ el Caribe, In: Anzola Perez E, Galinsky D, Morales Martinez F, Salas AR, Sanchez Ayndez M. La atención de los ancianos: un desafio para los años noventa. Washington: OPAS/ OMS, 1994. p.3-18. (Publicación Científica, n.546).

(19) Montesanti LT, Marques Junior OW, Quadrante ACR, Gorzoni ML, Ribeiro MCSA. Anamnese clinica $x$ geriátrica. Gerontologia 1999; 7(1): 8-16.

(20) Given BA, Given CW. Family caregiving for the elderly. Ann Ver Nurs Res 1999; 9: 77-101.

\section{Artigo recebido em 12/1 1/99}

\section{Artigo aprovado em 04/04/02}




\section{ANEXO I - INSTRUMENTO DE COE\LETA DE DADOS}

1. Caracterização das idosas

Idade:

Escolaridade:.

Condições de comunicação:

Dependência para as atividades de vida diária:

() fazer compras

( ) pegar ônibus

() cuidar das finanças

() cuidar das finanças

() tomar medicação adequadamente

( ) ir ao banheiro

( ) andar

() vestir-se

() tomar banho

( ) comer

( ) pentear-se

( ) ir ao banheiro

() ir para a cama e sair dela

\section{Caracterização dos cuidadores}

Idade: Sexo. Escolaridade:

Grau de parentesco com a idosa

Dificuldades que acredita encontra após a alta hospitalar

( ) habilidade para cuidar da idosa

( ) acomodações da casa

( ) cooperação de outros para cuidar do idoso

( ) relacionamento familiar

( ) situação financeira

( ) mudança no estilo de vida

( ) retorno ao serviço de saúde

() nenhuma

() outros: 